\title{
Paper
}

\section{Effect of Wire Diameter on Particle Size of Metal Nanosized Powder Prepared by Pulsed Wire Discharge}

\author{
Yoshinori Tokoi, Tsuneo Suzuki, Tadachika Nakayama, Hisayuki Suematsu, \\ Weihua Jiang and Koichi Niihara
}

Extreme Energy-Density Research Institute, Nagaoka University of Technology 1603-1 Kamitomioka, Nagaoka 940-2188, Japan.

Received December 14, 2007

\begin{abstract}
SYNOPSIS
Copper, silver and nickel nanosized powders were prepared using metal wires with different diameters in nitrogen gas by pulsed wire discharge. The diameter of the wire was changed from 0.05 to $0.3 \mathrm{~mm}$. The pressure of nitrogen and charged energy were fixed at $100 \mathrm{kPa}$ and $540 \mathrm{~J}$, respectively. After the discharge of the wires, the volume of plasma/vapor measured by high-speed photographs was almost constant even though the wire diameter was changed. On the other hand, the median diameter of copper, silver and nickel nanosized powders was decreased with decreasing the diameter of the wire. Therefore, the decrease in the median diameter accompanies the decrease in the density of the plasma/vapor.
\end{abstract}

KEY WORDS

pulsed wire discharge, metal, nanosized powder, particle size

\section{Introduction}

Metal nanosized powders are expected to be applied to nonliner optical devices, electroconductive nano filler for ink-jet wiring of fine pitch circuits and materials of electrodes for multi-layer ceramic capacitors ${ }^{1,2)}$.

Pulsed wire discharge (PWD) is one of the physical methods for nanosized powder preparation using highdensity plasma/vapor ${ }^{3-12}$. In this method, a metal wire is rapid heated by a pulsed high current in several microseconds to produce metal plasma/vapor. Then, the produced metal plasma/vapor expands into the ambient gas and is rapid cooled by the interaction with the ambient gas. Finally, many fine particles are formed giving nanosized powders. In inert gas such as argon, helium and nitrogen, metal nanosized powders were prepared. This method is featured by advantages in a high-purity and a high energy conversion efficiency for metal nanosized powder preparation ${ }^{6,7)}$. In addition, the metal nanosized powder with passivation layers can be prepared by wire evaporation in organic vapor $^{8)}$.

In the PWD process, the metal particle size can be decreased by decreasing the pressure of ambient gas, by increasing the energy inject into the wire and by increasing the high thermal conductivity of the ambient gas $^{9-11)}$. In the previous research, the particle size was found to be depended on the volume of plasma/vapor and the particle size was decreased with increasing the volume of plasma/ vapor. The above experiments were conducted using wires with a constant volume so that the change in the volume of plasma/vapor can vary the density of plasma/vapor. Thus, we expected that the density of plasma/vapor is a factor to control the particle size. Assuming the above hypothesis, another method to change the density of the plasma/vapor is to vary the wire volume discharged with fixed energy and gas pressure. On the other hand, no systematic experimental results were reported.

In this paper, we report our experimental results of copper, silver and nickel nanosized powder prepared using wires with different diameter by PWD.

\section{Experimental setup and condition}

Fig. 1 shows the schematic illustration of the experimental setup for nanosized powder prepared by PWD. This experimental apparatus composed of a typical discharge circuit, a nanosized powder preparation chamber and a nanosized powder collection filter. A wire was located between electrodes in the chamber. After the chamber evacuation by a rotary pump, the chamber was then filled with nitrogen gas at $100 \mathrm{kPa}$. A capacitor bank of $30 \mu \mathrm{F}$ was charged to a voltage of $6 \mathrm{kV}$ using a high-voltage DC power supply (H.V.). The wire exploded due to the pulsed high current by closing a spark gap. The powders prepared 


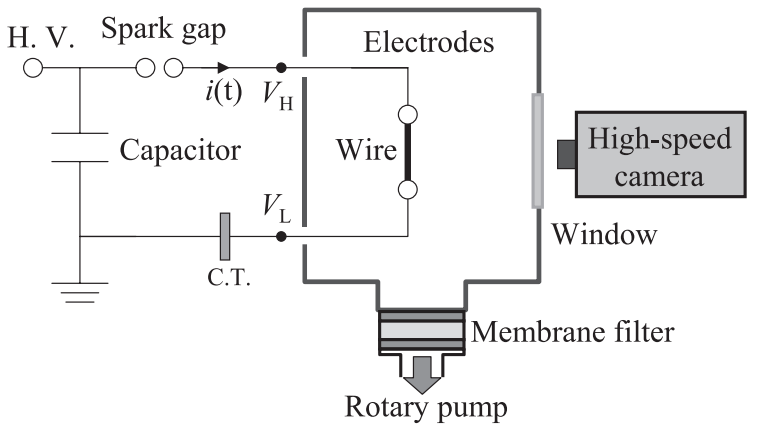

Fig.1 Experimental setup for PWD and typical discharge circuit.

in the chamber were collected on the surface of a membrane filter by evacuating the chamber.

In the experiments, the voltage between the electrodes and the current were measured by a digitized oscilloscope using two high-voltage probes and a current transformer (C.T.). Here, the voltage $(V(t))$ was obtained from subtraction between two probe signals obtained at inlet $\left(V_{\mathrm{H}}\right)$ and outlet $\left(V_{\mathrm{L}}\right)$ electrodes. The energy deposition $(E(t))$ was calculated from the measured $V(t)$ and current $(i(t))^{12)}$. The behavior of the plasma/vapor during the wire explosion was captured using a high-speed camera with a spectral response from $400 \mathrm{~nm}$ to $900 \mathrm{~nm}$ and the exposure time of $100 \mathrm{~ns}$. The prepared nanosized powders were analyzed by powder X-ray diffractometer (XRD) and transmission electron microscopy (TEM). The phases in the prepared powders were identified from the peak positions in the XRD patterns. The particle size distributions of prepared nanosized powders were evaluated by TEM images.

The experimental conditions for metal nanosized powder prepared are summarized in Table 1. The wires of $\mathrm{Cu}, \mathrm{Ag}$ and $\mathrm{Ni}$ with diameter $(d)$ of $0.05 \sim 0.3 \mathrm{~mm}$ and length of $25 \mathrm{~mm}$ were used in the preparation. The charged energy is calculated from the changed voltage and the capacitance to be $540 \mathrm{~J}$, which is fixed in the present experiments. The relative energy $(K)$ was defined as $E_{\mathrm{c}}$ divided by vaporization energy of the wire $\left(E_{\mathrm{v}}\right)$. The relative energy for the $\mathrm{Cu}$ wire of $d=0.05,0.1,0.2$ and $0.3 \mathrm{~mm}$ were $K=$ $199.6,49.9,12.5$ and 5.5 , respectively.

\section{Results and discussion}

Fig. 2 shows the (a) $V(\mathrm{t}),(\mathrm{b}) i(\mathrm{t})$ and (c) $E(t)$ waveforms during discharge of $\mathrm{Cu}$ wire with different diameter. The beginning of the increase in $i(\mathrm{t})$ was defined as time $(t)=0$. Each voltage waveform has a peak and the current waveform has a drop at the same time. About the voltage peak and current drop, we consider that the voltage peak was caused by an increase in the resistance of the wire or between electrodes due to the wire vaporization with wire heating and by a decrease in the resistance due to the plasma and/or high-temperature vapor ${ }^{12)}$. Therefore, the current rise after the current drop was due to arc discharge in the plasma/vapor. The voltage peak was delayed with the increasing the diameter of the wire. In the case of large diameter of the wire, the vaporization energy in the wire is larger than that in small diameter, and the time to becoming vapor is delayed with increasing the diameter of the wire. The current peak height around $10 \mu$ s was increased with decreasing the diameter of the wire. From this result, in the case of the small wire diameter, the majority of the charged energy is still stored in the capacitance even after the evaporation because the vaporization energy is small. Thus, the current peak increase after the current drop is able to contribute to arc discharge. The voltage and current waveform of silver and nickel were as same as the waveform of cooper as shown Fig. 2. Here, we define total deposited energy $\left(E_{\mathrm{t}}\right)$ as summation of $E(t)$ from $t=0$ to $90 \mu \mathrm{s}$, which is the end of the discharge. In addition, we define the ratio of deposited energy $\left(K_{\mathrm{d}}\right)$, which is a ratio of $E_{\mathrm{t}}$ and $E_{\mathrm{v}}$.

Table 1 Experimental conditions for copper, silver, nickel nanosized powder preparation.

\begin{tabular}{|c|c|c|c|c|c|c|c|c|c|c|c|c|}
\hline \multirow[b]{2}{*}{ Wire } & Species & \multicolumn{4}{|c|}{$\mathrm{Cu}$} & \multicolumn{4}{|c|}{$\mathrm{Ag}$} & \multicolumn{3}{|c|}{$\mathrm{Ni}$} \\
\hline & Length, $l[\mathrm{~mm}]$ & & & & & & & 25 & & & & \\
\hline & Diameter, $d[\mathrm{~mm}]$ & 0.3 & 0.2 & 0.1 & 0.05 & 0.3 & 0.2 & 0.1 & 0.05 & \begin{tabular}{l|l}
0.25 & 0.2
\end{tabular} & 0.1 & 0.05 \\
\hline \multicolumn{2}{|c|}{ Vaporization Energy, $E_{\mathrm{v}}[\mathrm{J}]$} & 97.4 & 43.3 & 10.8 & 2.7 & 48.9 & 21.8 & 5.4 & 1.4 & \begin{tabular}{l|l}
91.5 & 58.5
\end{tabular} & 14.6 & 3.7 \\
\hline \multicolumn{6}{|c|}{ Gas Species } & \multicolumn{4}{|c|}{$\mathrm{N}_{2}$} & & & \\
\hline \multicolumn{2}{|c|}{ Pressure $[\mathrm{kPa}]$} & & & & & \multicolumn{4}{|c|}{100} & & & \\
\hline \multicolumn{2}{|c|}{ Capacitance $[\mu \mathrm{F}]$} & & & & & \multicolumn{4}{|c|}{30} & & & \\
\hline \multicolumn{2}{|c|}{ Charged Voltage [kV] } & & & & & \multicolumn{4}{|c|}{6} & & & \\
\hline \multicolumn{2}{|c|}{ Charged Energy, $E_{\mathrm{c}}[\mathrm{J}]$} & & & & & \multicolumn{4}{|c|}{540} & & & \\
\hline Relati & $\mathrm{gy}, K\left(E_{\mathrm{t}} / E_{\mathrm{v}}\right)$ & 5.5 & 12.5 & 49.9 & 199.6 & 11.0 & 24.8 & 99.3 & 397.2 & \begin{tabular}{l|l}
5.9 & 9.2
\end{tabular} & 36.9 & 147.6 \\
\hline
\end{tabular}




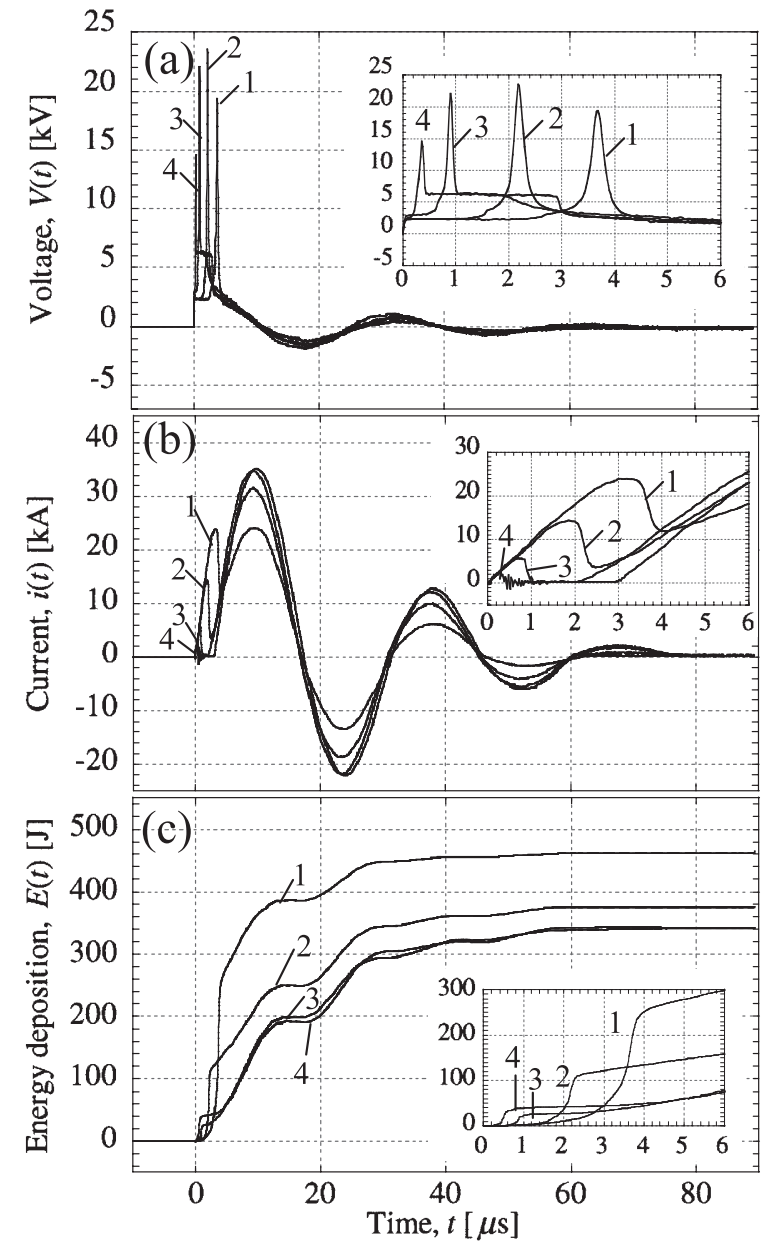

Fig.2 Voltage, current waveforms and energy deposition during the copper wire discharge in nitrogen gas. (a) voltage waveforms, (b) current waveforms and (c) energy deposition. Diameter of copper wire is \# 1: 0.3, \#2: 0.2, \#3: $0.1, \# 4: 0.05 \mathrm{~mm}$.

Fig. 3 shows the dependence of relative energy on (a) $E_{\mathrm{t}}$ and (b) $K_{\mathrm{d}}$ of different diameter of the copper, silver and nickel wire diameter. $E_{\mathrm{t}}$ was decreased with increasing $K$ which is increased with deceasing the diameter of the wire. On the other hand, $K_{\mathrm{d}}$ is increased linearly with increasing $K$ as shown Fig. 3 (b). The energy inject per unit wire volume was increased with decreasing the diameter of the wire.

Fig. 4 shows the XRD patterns of nanosized powder prepared using (a) $\mathrm{Cu}$, (b) Ag and (c) Ni wires with different diameter. The vertical straight lines in Fig. 4 show diffraction peak positions for $\mathrm{Cu}, \mathrm{Ag}$ and $\mathrm{Ni}$ according to International Center for Diffraction Data (ICDD) ${ }^{13)}$. Since the powders have XRD peaks for $\mathrm{Cu}, \mathrm{Ag}$ and $\mathrm{Ni}$, respectively, they are identified as $\mathrm{Cu}, \mathrm{Ag}$ and $\mathrm{Ni}$ powders.

Fig. 5 shows bright-field TEM images of (a) $\mathrm{Cu}$, (b) $\mathrm{Ag}$ and (c) Ni nanosized powders prepared at the different wire diameter. Shape of powders prepared at all conditions is
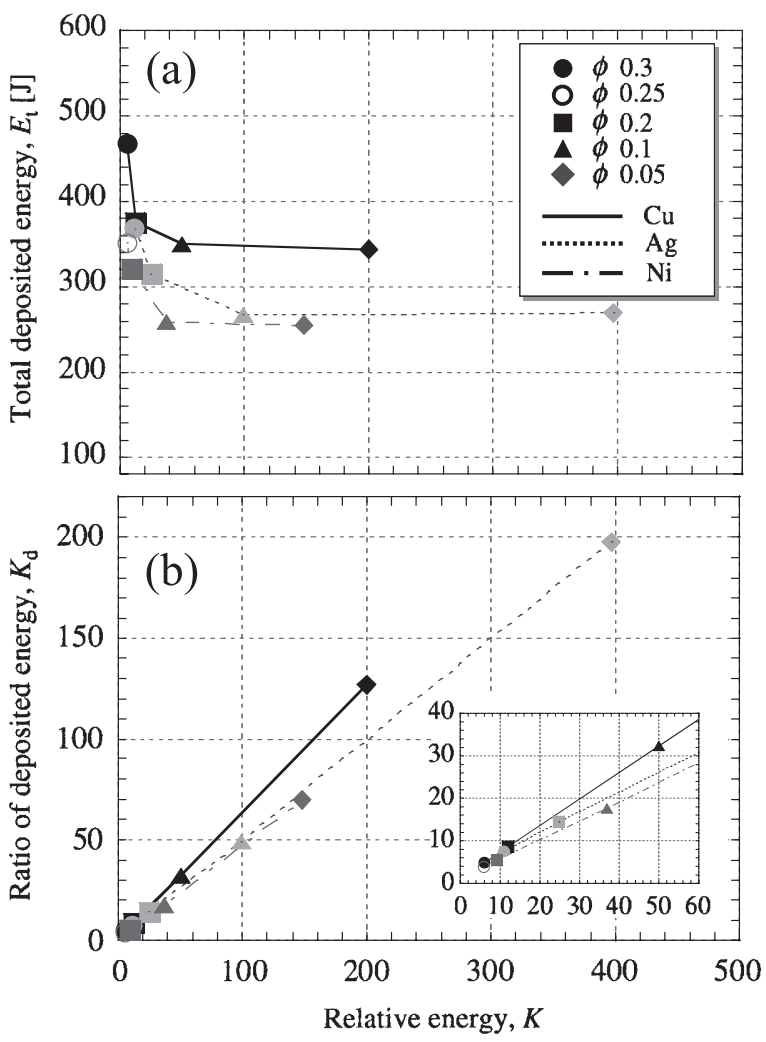

Fig.3 Dependence of (a) total deposited energy $\left(E_{\mathrm{t}}\right)$ and (b) ratio of deposited energy $\left(K_{\mathrm{d}}\right)$ on the relative energy $(K)$.

spherical.

Fig. 6 shows the particle size distribution of (a) $\mathrm{Cu}$, (b) $\mathrm{Ag}$ and (c) Ni nanosized powders obtained from 1000 particles including those in Fig. 5. The solid lines are fitted log-normal distribution curves to the experiment results ${ }^{9)}$. $D_{50}$ is the median diameter and $\sigma_{\mathrm{g}}$ is the geometric standard deviation. The smallest median diameters of $\mathrm{Cu}, \mathrm{Ag}$ and Ti particle were 11.4, 12.3 and $9.7 \mathrm{~nm}$, respectively. By changing the wire diameter, for example, in the case of $\mathrm{Cu}$ particles, $D_{50}$ was changed from 35.3 to $11.4 \mathrm{~nm}$ and $\sigma_{\mathrm{g}}$ was slightly changed from 1.5 to 1.45 .

Fig. 7 shows the dependence of $D_{50}$ of $\mathrm{Cu}, \mathrm{Ag}$ and $\mathrm{Ni}$ nanosized powders on $K_{\mathrm{d}}$. The median diameter of $\mathrm{Cu}$, $\mathrm{Ag}$ and $\mathrm{Ni}$ nanosized powder was decreased with decreasing $K_{\mathrm{d}}$, which was increased with decreasing the diameter of the wire.

Fig. 8 shows high-speed photographs during $\mathrm{Cu}$ wire explosion. In Fig. 8, (a) is the schematic representation, and (b) - (e) are high-speed photographs of wire explosion. The area of the light emission and the luminescence time was almost the same as the change in the diameter of the wire.

Fig. 9 shows the relation of $K$ to the volume of plasma/ 

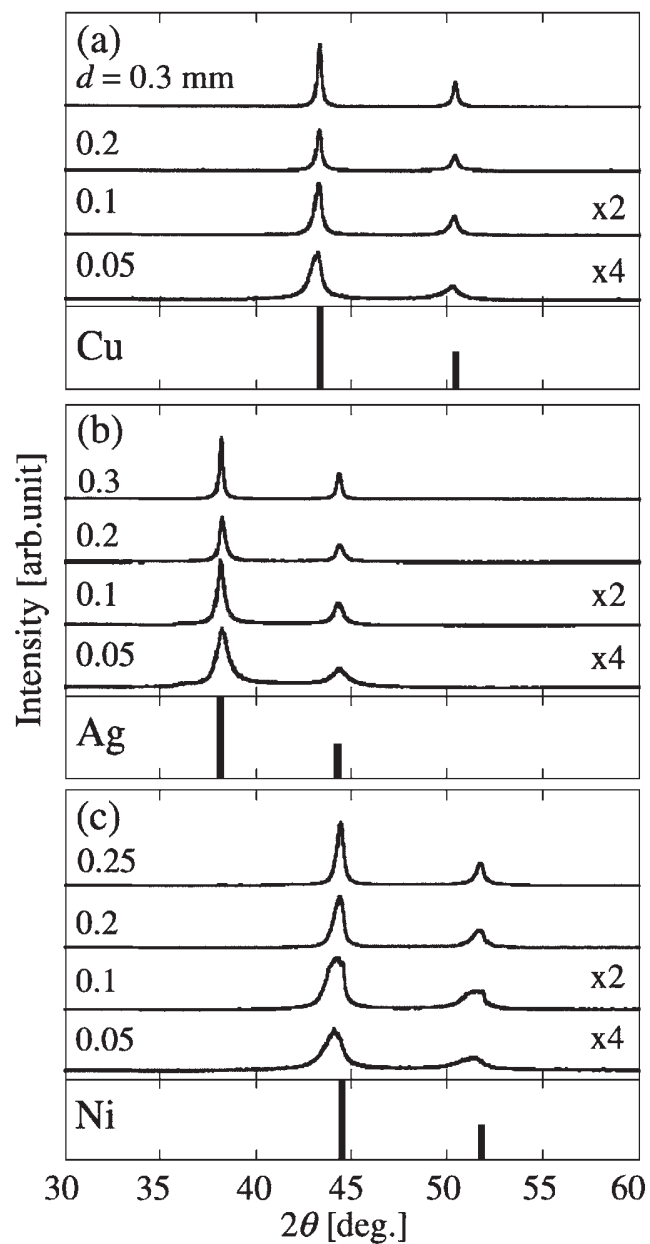

Fig.4 XRD patterns of (a) copper, (b) silver and (c) nickel nanosized powder prepared at different diameter of the wire.

vapor $\left(V_{\text {exp }}\right)$ and the density of plasma/vapor $\left(D_{\text {exp }}\right)$ at $t=$ $70 \mu$ s as shown in Fig. 8(b) - (d), where $V_{\text {exp }}$ was calculated from Fig. 8 assuming plasma/vapor being spherical and the density of plasma/vapor was calculated by $V_{\text {exp }}$ and the weight of the wire. $V_{\exp }$ was decreased a little with decreasing the diameter of the wire. However, $D_{\exp }$ was decreased greatly with decreasing the diameter of the wire. From Figs. 7 and 9, the particle size was found to be decreased with decreasing $D_{\text {exp }}$.

When the particles grow by coagulation after the nucleation, the coagulation of particles was suppressed by decreasing $D_{\text {exp. }}$. Thus, this is considered to be the reason of the particle size dependence on $D_{\text {exp. }}$.

\section{Conclusions}

We carried out preparation of copper, silver and nickel nanosized powders by PWD and obtained the following conclusions. The ratio of deposited energy is increased linearly with increasing the relative energy which is

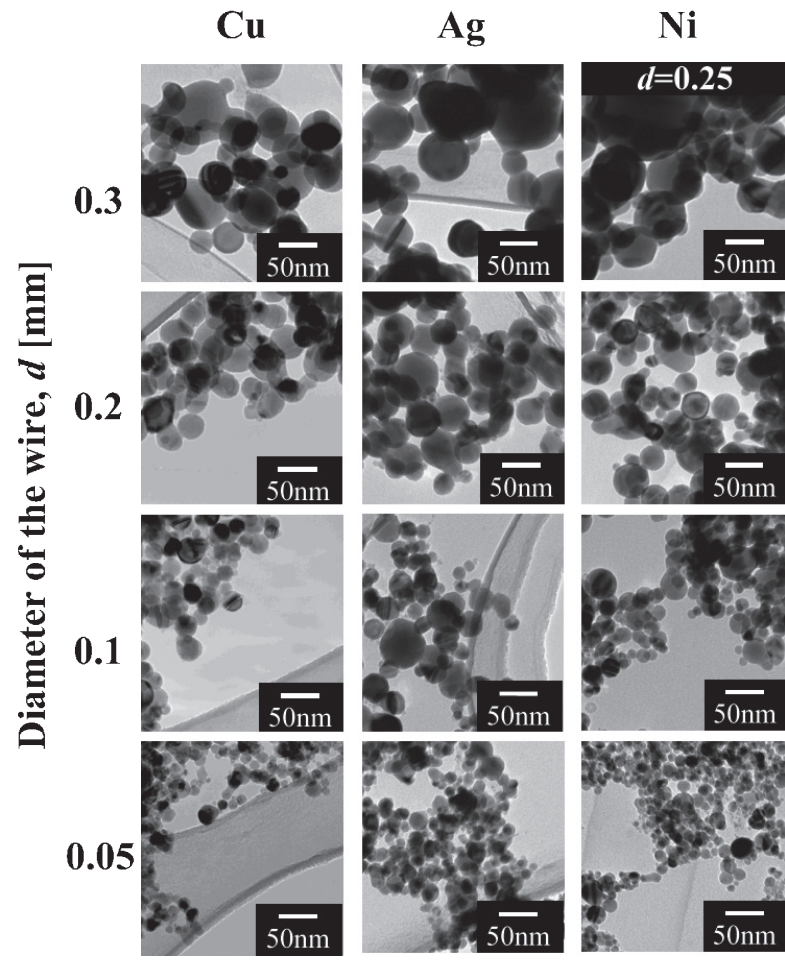

Fig.5 Bright-field TEM image of copper, silver and nickel nanosized powders at different diameter of the wire.

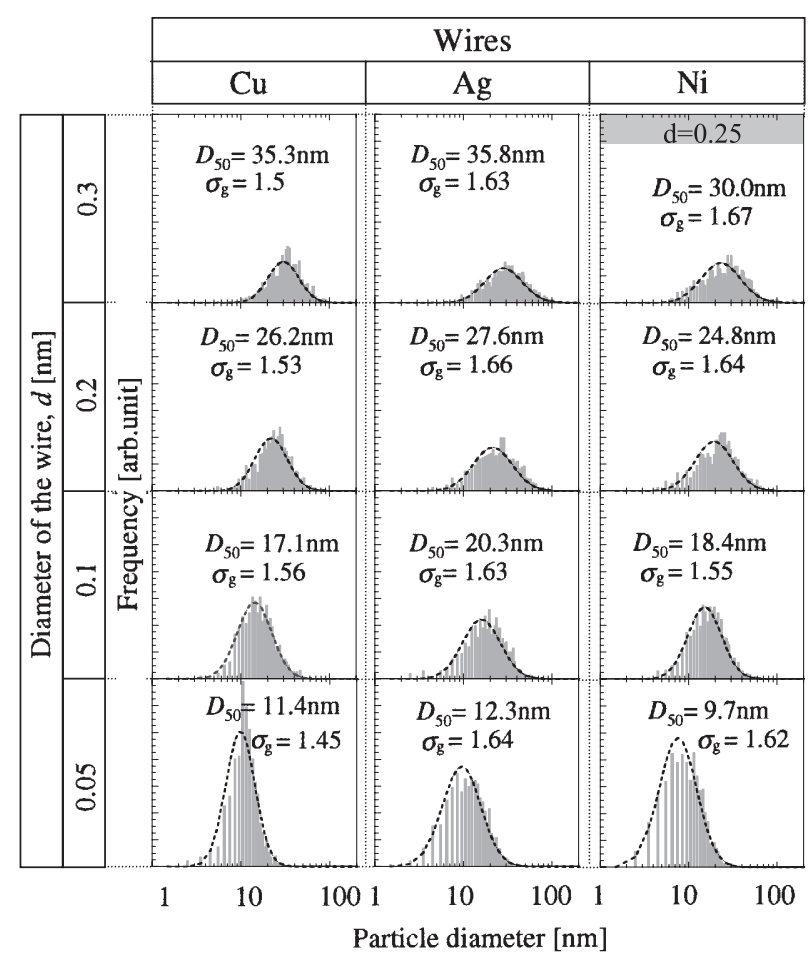

Fig.6 Particle distributions of copper, silver and nickel nanosized powders at different diameter of the wire.

increased with deceasing the diameter of the wire. From XRD pattern, the prepared nanosized powders are 


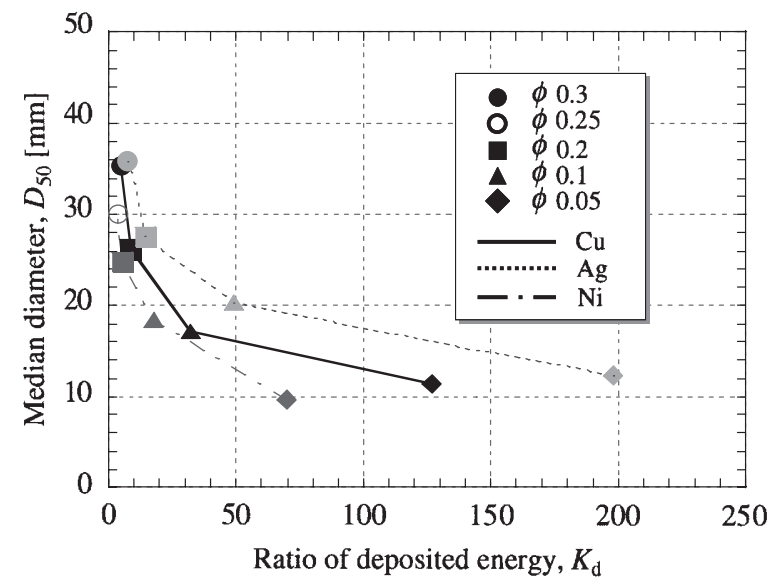

Fig.7 Dependence of median diameter of copper, silver and nickel nanosized powders on the ratio of deposited energy $\left(K_{d}\right)$.

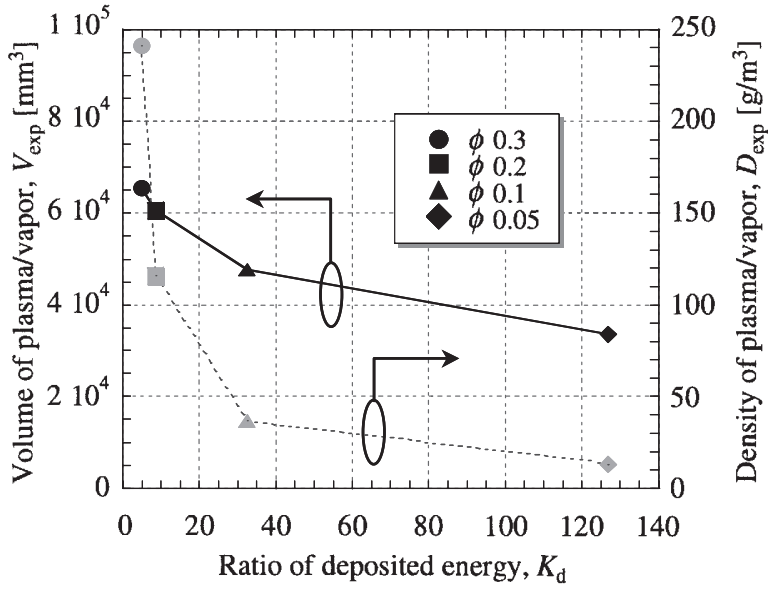

Fig.9 Relation of the volume of copper plasma/vapor $\left(V_{\text {exp }}\right)$ and density of copper plasma/vapor $\left(D_{\text {exp }}\right)$ on ratio of deposited energy $\left(K_{\mathrm{d}}\right)$.

(a)

(b)

(c)

(d)

(e)
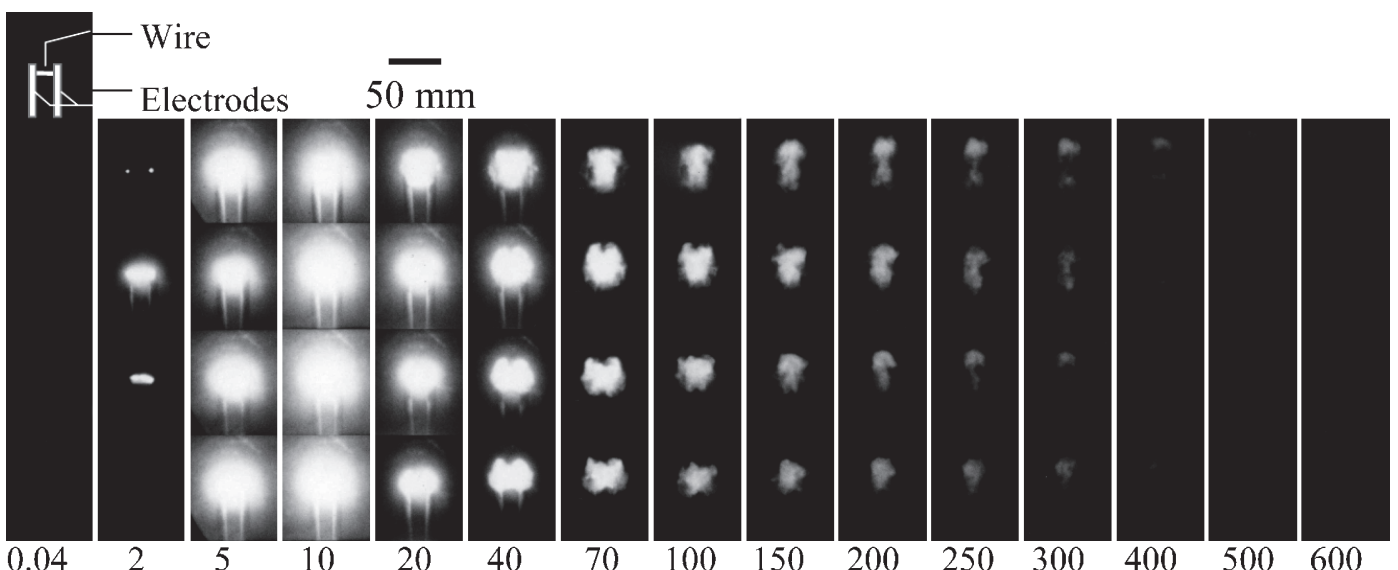

Time, $t[\mu \mathrm{s}]$

Fig.8 High-speed photographs during wire explosion at copper wire in nitrogen gas. (a) schematic illustration, (b) - (f) high-speed photographs. Diameter of copper wire is (b) 0.3 , (c) 0.2 , (d) 0.1 and (e) $0.05 \mathrm{~mm}$.

identified as copper, silver and nickel, respectively. The particle size of copper, silver and nickel was decreased with decreasing the diameter of the wire. From high-speed photographs of copper nanosized powder prepared, the volume of plasma/vapor was not affected by decreasing the diameter of the wire. However, the density of plasma/ vapor was decreased greatly with decreasing the diameter of the wire. Therefore, the decrease in the particle size was caused by the decrease in the density of plasma/vapor and by the suppression of coagulation in the PWD process.

\section{Acknowledgment}

This study is supported by Research Fellowships of the Japan Society for the Promotion of Science for Young Scientists and Japan Science and Technology Agency.

\section{Reference}

1) J.Chung, S.Ko, N.R.Bieri, C.P.Grigoropoulos and D.Poulikakos: "Conductor Microstructures by Laser Curing of Printed Gold Nanoparticle Ink", Appl. Phys. Lett., 84(2004)801-803.

2) D.H.Im, S.H.Hyun, S.Y.Park, B.Y.Lee and Y.H.Kim: "Preparation of Ni Paste Using Binary Powder Mixture for Thick Film Electrodes", Mater. Chem. Phys., 96 (2006)228-233.

3) M.Umakoshi, H.Ito and A.Kato: "Preparation of $\mathrm{TiO}_{2}$ Particles by Means of Wire Exploding Method", Yogyo-Kyokai-Shi, 95(1987) 124-129.

4) V.Ivanov, Y.A.Kotov, O.H.Samatov, R.Böhme, H.U.Karow and G.Schumacher: "Synthesis and Dynamic Compaction of Ceramic Nano Powders by Techniques Based on Electric Pulsed Power", 
Nanostructured Materials, 6(1995)287-290.

5) W.Jiang and K.Yatsui: "Pulsed Wire Discharge for Nanosized Powder Synthesis", IEEE Trans. Plasma Sci., 26(1998) 1498-1501.

6) H.Suematsu, S.Nishimura, K.Murai, Y.Hayashi, T.Suzuki, A.Yamazaki, K.Seki and K.Niihara: "Pulsed Wire Discharge Apparatus for Mass Production of Copper Nanopowders", Rev. Sci. Instrum., 78(2007) 056105.

7) Y.A.Kotov: "Electric Explosion of Wires as a Method for Preparation of Nanopowders", J. Nanoparticle Research, 5(2003)539-550.

8) K.Murai, Y.Watanabe, Y.Saito, T.Nakayama, H.Suematsu, W.Jiang, K.Yatsui, K.H.Shim and K.Niihara: "Preparation of Copper Nanoparticles with an Organic Coating by a Pulsed Wire Discharge Method", J. Ceram. Proc. Res., 8(2) (2007) 114-118.

9) K.Murai, C.Cho, H.Suematsu, W.Jiang and K.Yatsui: "Particle Size Distribution of Copper Nanosized Powders Prepared by Pulsed Wire Discharge", IEEJ
Trans. FM, 125(2005)39-44.

10) Y.Tokoi, T.Suzuki, T.Nakayama, H.Suematsu, W.Jiang, K.Yatsui and K.Niihara: "Effect of Energy Deposition on Particle Size of Metal Nanosized Powder Prepared by Pulsed Wire Discharge", Abstracts of the 13th 21st Century COE Joint Int. Symp., (2006)56.

11) K.Murai, H.Suematsu, W.Jiang and K.Yatsui: "Ambient Gas Species Dependence of Size Distribution in $\mathrm{Cu}$ Nanoparticles Prepared by Pulsed Wire Discharge", Abstract of the 2004 Int. Symp. Organic and Inorganic Electronic Materials and Related Nanotechnologies, (2004) 246.

12) C.Cho, Y.Kinemuchi, H.Suematsu, W.Jiang and K.Yatsui: "Enhancement of Nitridation in Synthesis of Aluminum Nitride Nanosize Powders by Pulsed Wire Discharge", Jpn. J. Appl. Phys., 42(2003) 17631765.

13) Powder Diffraction File, ICDD International Center for Diffraction Data, Swanson, Tatge: $\mathrm{Cu}$ (04-0836), $\mathrm{Ag}$ (04-0783) and Ni (04-0850). 